\title{
Epidemiological Profile of Diagnosed Disorders in Urological Consultation at Sylvanus Olympio Teaching Hospital in Lome
}

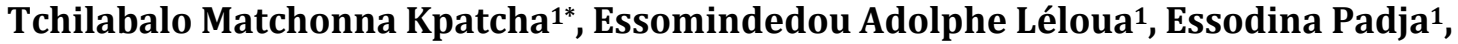

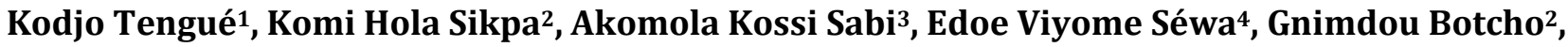 \\ Obube Amégayibor1, Tsipa Anoukoum ${ }^{1}$, Ekoue David Dosseh ${ }^{5}$
}

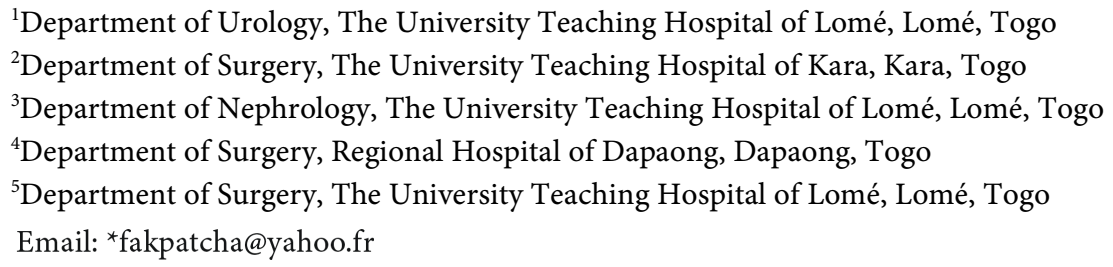

How to cite this paper: Kpatcha, T.M., Léloua, E.A., Padja, E., Tengué, K., Sikpa, K.H., Sabi, A.K., Séwa, E.V., Botcho, G., Amégayibor, O., Anoukoum, T. and Dosseh, E.D. (2017) Epidemiological Profile of Diagnosed Disorders in Urological Consultation at Sylvanus Olympio Teaching Hospital in Lome. Open Journal of Urology, 7, 167-172. https://doi.org/10.4236/oju.2017.710020

Received: August 10, 2017

Accepted: September 26, 2017

Published: September 29, 2017

Copyright $(9) 2017$ by authors and Scientific Research Publishing Inc. This work is licensed under the Creative Commons Attribution International License (CC BY 4.0).

http://creativecommons.org/licenses/by/4.0/

\begin{abstract}
Context: Thanks to the increase in the number of urologists in Togo, urological activity is improving rapidly. Objective: This study aims at presenting the epidemiological aspects of the diseases diagnosed in urology consultation at the Sylvanus Olympio Teaching Hospital in Lome. Materials and Methods: This research was a two-year retrospective and descriptive study. The data for the analysis were collected from the records of patients received in consultation for urological pathology. The parameters taken into account are: frequency, age, sex, occupation, patient history and diagnosis. Results: 602 patients were admitted at the department of urology within two years, with an annual frequency of 301 . The average age of the patients was $48.63 \pm 19.69$ years; the sex ratio (M/F) was equal to 12.08. Patients over 60 years of age accounted for $33.3 \%$ of the patients seen. The medical history of 88 cases showed that the bladder catheterization was most frequent $(22$ cases) followed by hypertension (15 cases). Benign prostatic hyperplasia was the most frequently diagnosed pathology accounting for $24.9 \%$ of the consultations. Conclusion: Benign prostatic hyperplasia is the most frequent pathology in urology consultation at the Sylvanus Olympio Teaching Hospital in Lome.
\end{abstract}

\section{Keywords}

Epidemiology, Consultation, Urology, Sylvanus Olympio Teaching Hospital, Lome 


\section{Introduction}

Urological pathologies have always existed among the Togolese population, but their frequency is poorly known, especially in hospitals. Socio-cultural considerations in African countries constitute a restraint to the expression for the need of care for the diseases of the elderly patients and the urogenital system. But in recent years, the increase in the number of urologists and efforts in the information in order to de-dramatize urogenital disease have increased the demand for urological care in both public and private hospitals. In most African countries, urological emergencies are dominated by urine retention and urogenital infections [1] and they account for a large number of admissions in urology services [2]. In Togo, the urology department has no staff waiting room of itself and the outpatient clinics are the main ways for admission into the service. The true frequency of these consultations is not known but it seems to have increased markedly in recent years. The objective of this study was to present the epidemiological aspects of urological diseases in an outpatient setting at the Sylvanus Olympio Teaching Hospital in Lome.

\section{Materials and Methods}

We conducted a retrospective and descriptive study over two years. Apart from the consultations made by the emergency team, the data collection material was the consultation of files of the urology department of the Teaching Hospital of Sylvanus Olympio of Lome. The Urology department of the hospital does not have a special waiting room. All the records of patients received in urology and whose final diagnosis revealed a urological pathology were taken into consideration for the purpose of this study. Incomplete files as well as records that did not allow a clear diagnosis were not included. The data collection was done on the basis of a pre-established sheet; the study criteria were: frequency of consultations, age, sex, occupation, patient history and diagnosis. The data was analyzed using the Epi Info software version 6.04d and graphics made by Excel.

\section{Results}

In two years, 602 patients in urology were recorded. The results shows that the male sex was predominating with $92.3 \%(\mathrm{n}=556)$ and the sex ratio $(M / F)$ was 12.08. The age of the patients who were consulted varied from 2 years to 98 years with an average of $48.63 \pm 19.69$ years. Elderly patients were widely represented; Indeed, the age groups from 60 to 70 years, and above 70 represent respectively $21.2 \%(\mathrm{~N}=128)$ and $12.1 \%(\mathrm{n}=73)$, as indicated in Figure 1.

On the whole, 352 records included the patient's occupation. The unemployed patients reflected the majority with a total of 250 cases corresponding to $41.5 \%$ of the total number studied. From the eighty-eight files, medical and surgical histories were recorded. The most common case observed was the transurethral urinal bladder catheterization (22 cases), followed by hypertension (15 cases). All of the antecedents are presented in Table 1. 


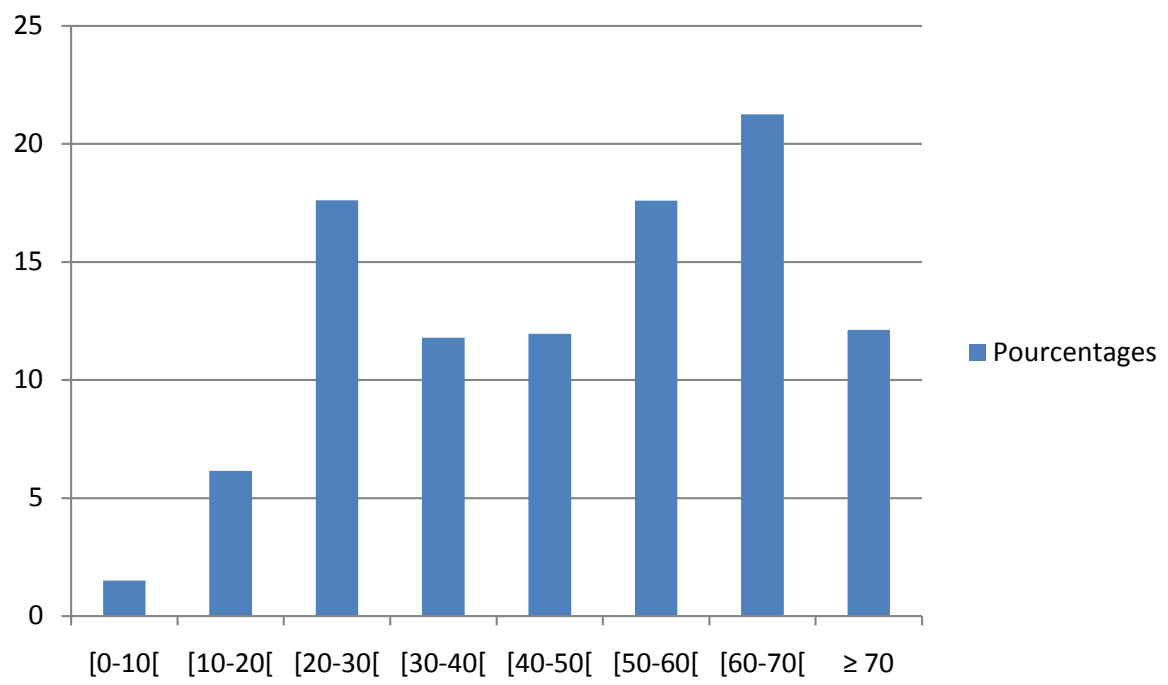

Figure 1. Distribution of patients according to age group.

Table 1. Different histories of patients.

\begin{tabular}{cccc}
\hline Type of History & Different Histories & Number $(\mathbf{n}=\mathbf{8 8})$ & Percentage (\%) \\
\hline Bladder Catheterization & 22 & 25 \\
Hypertension & 15 & 17 \\
Medical & Diabetes & 7 & 7.9 \\
& Medical Sickle Cell Anemia & 4 & 4.5 \\
Urethritis & 9 & 10.2 \\
Hematuria & 11 & 12.5 \\
\hline \multirow{3}{*}{ Surgical } & Genitalia Traumatism & 1 & 1.1 \\
& Cystoscopy & 1 & 1.1 \\
& Hernia Inguinal Cure & 8 & 9 \\
& Prostate Surgery & 7 & 7.9 \\
& Caesarean Section & 2 & 2.2 \\
& Hysterectomy & 1 & 1.1 \\
\hline
\end{tabular}

The nature of affections was multiple, tumor pathologies were the most frequent with $36.7 \%$ (221/602), and followed by infectious diseases with $22.6 \%$ (136/602). The distribution of the various conditions is shown in Table 2.

Tumor pathology was dominated by benign and malignant prostatic tumors in the respective proportions of 150 cases and 36 cases, accounting for $24.9 \%$ and $5.9 \%$ respectively of all cases studied. Other tumors were bladder tumors (24 cases), testicular tumors (7 cases) and renal tumors (4 cases). The infectious pathology was mainly represented by urethritis (45 cases), orchiepididymitis (36 cases) and cystitis (17 cases). Urethral stenosis recorded $8.4 \%(\mathrm{n}=51)$ and no correlation was found with urethral catheterization antecedents; urinary lithiasis were diagnosed in $3.4 \%(n=21)$ of the cases, and male sexual disorders in $5.8 \%$ $(\mathrm{n}=35)$. 
Table 2. Distribution of the different affections diagnosed.

\begin{tabular}{|c|c|c|}
\hline Affections & Number of cases & Percentage (\%) \\
\hline \multicolumn{3}{|l|}{ Tumor pathologies: } \\
\hline - $\mathrm{BPH}$ & 150 & 24.9 \\
\hline - Prostate cancer & 36 & 5.9 \\
\hline - Bladder cancer & 24 & 3.9 \\
\hline - Testicular cancer & 7 & 1.1 \\
\hline - Kidney cancer & 4 & 0.6 \\
\hline \multicolumn{3}{|l|}{ Infectious pathologies: } \\
\hline - Urethritis & 46 & 7.4 \\
\hline - Orchyepididymite & 36 & 5.9 \\
\hline - Cystitis & 17 & 2.8 \\
\hline - Prostatitis & 16 & 2.6 \\
\hline - Pyelonephritis & 10 & 1.6 \\
\hline - Renal abscess & 8 & 1.3 \\
\hline - Gangrene of Fournier & 4 & 0.6 \\
\hline \multicolumn{3}{|c|}{ External genitalia pathologies: } \\
\hline - Sexual disorders & 35 & 5.8 \\
\hline - Hydrocele & 20 & 3.3 \\
\hline - Varicocele & 15 & 2.4 \\
\hline - Spermatic cord cyst & 12 & 1.9 \\
\hline - Testicular ectopia & 5 & 0.8 \\
\hline - Lapeyronie's disease & 3 & 0.4 \\
\hline \multicolumn{3}{|l|}{ Unclassified pathologies: } \\
\hline - Urethral stenosis & 51 & 8.4 \\
\hline - Inguinal hernia & 34 & 5.6 \\
\hline - Urinary lithiasis & 21 & 3.4 \\
\hline - Hydronephrosis & 21 & 3.4 \\
\hline - Enuresis & 12 & 1.9 \\
\hline - Renal cyst & 10 & 1.4 \\
\hline - Vesico-vaginal fistula & 3 & 0.4 \\
\hline - Cystocele & 2 & 0.3 \\
\hline TOTAL & 602 & 100 \\
\hline
\end{tabular}

BPH: Benign Prostatic Hyperplasia.

\section{Discussion}

In two years period, 602 patients were received externally in the Urology-andrology department of Sylvanus Olympio Teaching Hospital. The weaknesses of our study reside in the lack of information provided in the files. The lack of information has reduced the number of usable files. Nevertheless, the selected sample was representative enough for an objective analysis.

\subsection{Frequency, Sex and Age}

The number of annual urological consultations is relatively low at the Teaching Hospital of Lome. The limited human resources at the reception constitute a factor which does not favor the expansion of urological activities, particularly that of external consultation. Although patients over 60 years of age are involved in about one third of the consultations in our study, the average age of our patients is relatively low. Urological pathology is known to be pathology of the ag- 
ing person [3] [4]. As reported by the authors cited above, urological diseases are more frequent after 50 and their prevalence increases with age. This is the case among our study population sample where more than half was over 50 . The peak frequency observed in the thirties is related to the frequent occurrence of sexually transmitted infections at these ages.

The population consulted in urology was largely dominated by male subjects. This male predominance is related to the nature of the urological pathologies that are dominated in our context by prostatic tumors. The second reason is that gynecology and urology share some of the woman's affections, including urinary incontinence and urinary tract infections. Also, Andrology, which is a subspecialty of urology, only concerns the man.

\subsection{Etiological Aspects}

Less than one-third of outpatients were diagnosed with prostate tumors and the number is increasing in the country because of sensitization campaigns about the need for early detection of prostate cancer permitting doctors to get data on sick patients. Many people over fifty years of age opt for an annual prostate check-up either because they have a family history of prostatic tumors or because of personal motivation to ensure active prevention. The benign prostatic hypertrophy diagnosed in one quarter of the patients in our study has a galloping incidence and in the years to come will be a real problem for the Togolese urologist who is often overwhelmed by the high demand in urological care.

The important position occupied by the urological tumors in our series corroborate the results of the histological series of Darré, on all the tumors diagnosed in the laboratory of pathological anatomy of the Teaching Hospital over a period of twenty years. The author reported $14.7 \%$ of urological tumors [5]. These tumors were also dominated by prostate cancer, followed by bladder cancer. The current accessibility to increasingly efficient diagnostic methods, may it be medical imaging or biology, confirms the presence of cancer pathologies in our country with a consequence of continuous growth in the number of cancer cases diagnosed.

Urethritis was the predominant infectious disease in our patients; the young age of our informants and the large male predominance are surely the reasons. It is indeed a sexually active age group with risks of contamination by sexually transmitted germs. The gangrene of the external genitals was rarely a reason for consultation because its discovery is often in an emergency context where the emergency team ensures the first aid before the transfer of the patients in the urology department.

In two years, only 35 patients had been seen for sexual problems. This low frequency of sexual disorders in our hospitals can be explained by the reluctance of the Togolese people to seek care for this type of pathology due to decency. Patients of the third age do not often consider sexual disorders and are only discovered by the physician-directed questions in patients with risk factors for the erectile ill-functions. 


\section{Conclusion}

This study has shown that the most frequent tumors observed in urological consultation in Lome are the tumorous pathologies and the benign prostatic hypertrophy accounting for about a quarter of all diagnoses.

\section{Acknowledgements}

We thank Professor ESSIZEWA Komlan for his valuable contribution.

\section{References}

[1] Fall, B., Diao, B., Fall, P.A., Diallo, Y., Sow, Y., Ondongo, A.A.M., Diagana, M., Ndoye, A.K., Ba, M. and Diagne, B.A. (2008) Les urgences urologiques en milieu hospitalier à Dakar: aspects épidémiologiques, cliniques et thérapeutiques. [Urological Emergencies in Hospital in Dakar: Epidemiological, Clinical and Therapeutic Aspects.] Progrès en Urologie, 18, 650-653. https://doi.org/10.1016/j.purol.2008.04.004

[2] Diallo, M.B., Bah, I. and Baldé, I. (1996) Les urgences urologiques au CHU Ignace Deen etude retrospective. [Urological Emergencies at Ignace Deen Teaching Hospital: A Retrospective Study.] Guinée Médicale, 10, 9-14.

[3] Mondet, F., Chartier-Kastler, E., Yonneau, L., Bohin, D., Barrou, B. and Richard, F. (2002) Epidémiologie des urgences urologiques en centre hospitalier universitaire. [Epidemiology of Urological Emergencies in University Hospital.] Progrès en Urologie, 12, 437-442.

[4] Bauvin, E., Remontet, L., Grosclaude, P., le réseau Francim and le CépiDc (2003) Incidence et mortalité du cancer de la prostate en France: tendances évolutives entre 1978 et 2000. [Incidence and Mortality of Prostate Cancer in France: Evolutionary Trends between 1978 and 2000.] Progrès en Urologie, 13, 1334-1339.

[5] Darré, T., Amégbor, K., Kpatcha, M., Tengué, K., Sonhaye, L., Doh, K., Tchaou, M., Anoukoum, S. and Napo-Koura, G. (2014) Cancers urologiques au Togo: profil histoépidémiologique à propos de 678 cas. [Urological Cancers in Togo: Histoepidemiological Profile of 678 Cases.] Journal Africain du Cancer, 6, 27-31. https://doi.org/10.1007/s12558-013-0296-3 